\title{
Fazit: Wozu taugen Kennzahlen und Kennzahlensysteme?
}

Das Anwendungsbeispiel liest sich sperrig. Es ist nicht einfach zu verstehen und es vermengt objektiv nachvollziehbare Schritte mit solchen, die durchaus auch anders hätten gemacht werden können. Aber die Idee eines Kennzahlensystems wird deutlich: Es ist sowohl ein System mathematischer Verknüpfungen von Inputdaten, um aus einem „Zahlensalat“ einige wenige Schlüsselkenngrößen zu machen, als auch ein Managementinstrument, das die unternehmerische Zielsetzung widerspiegelt.

Kennzahlensysteme dienen der Vereinfachung. Und damit wird eine Forderung aus Kap. 2 verständlich: Die Dokumentation. Jeder, der mit Kennzahlen bzw. Kennzahlensystemen arbeitet, muss wissen, wie sie zustande kommen und wie sie zu nutzen sind. Schon ein Missverständnis im Zeitbezug oder in der Abgrenzung der Inputdatenbereiche führt zu einem Fehler, der - das ist das Fatale - nicht auffällt, wenn nur auf das Endergebnis geschaut wird. Werden sie jedoch richtig genutzt, sind sie fantastische Instrumente, die helfen, eine komplexe unternehmerische Welt zu vereinfachen, um sie begreifen und gestalten zu können. 